13

\title{
Влияние дипольной поляризации эмитирующей поверхности на пороги автоэмиссии многоострийных кремниевых катодных матриц
}

\author{
(C) P.К. Яфраров
}

Саратовский фрилиал Института радиотехники и электроники им. В.А. Котельникова РАН, Саратов, Россия

E-mail: pirpc@yandex.ru

Поступило в Редакцию 30 марта 2018 г.

Исследованы закономерности изменений структурно-фазового состава, морфологических и автоэмиссионных характеристик поверхностно структурированных кремниевых пластин различных типов проводимости. Показано, что применение фторуглеродной плазмы в процессе структурирования с использованием углеродного масочного покрытия позволяет получать заданные токи автоэмиссии кремниевых катодных матриц при изменении в широком диапазоне напряженностей внешних электрических полей независимо от изменения коэффициентов усиления поля эмиссионных выступов. Установлена превалирующая роль дипольной поляризации при полевой эмиссии электронов в поверхностно модифицированных кремниевых структурах.

DOI: 10.21883/PJTF.2018.13.46329.17313

Основным недостатком, который препятствует широкому использованию кремния в создании интегральных схем вакуумно-плазменной микроэлектроники, являются высокие управляющие напряжения для получения автоэмиссии. Традиционный путь их снижения для всех видов материалов автокатодов - уменьшение радиусов эмитирующих острий и диаметров отверстий в управляющих электродах, что определяется уровнем применяемой технологии изготовления. Наиболее значительные успехи получены при создании на кремнии острийных решеток автоэмиссионных катодов с радиусом кривизны атомарных размеров (менее $1 \mathrm{~nm}$ ) [1], что позволяет существенно понизить рабочее напряжение. Однако усложнение технологии изготовления таких устройств сопровождается, как правило, снижением их надежности и увеличением 
себестоимости. В связи с этим большой как фундаментальный, так и прикладной интерес представляют исследования альтернативных путей, направленных на улучшение эмиссионных характеристик автокатодов, которые были бы связаны не только с конструктивными, но и с физико-химическими модификациями эмиссионных свойств кремниевых кристаллов.

В работе [2] показано, что плазменная обработка поверхностей полупроводников с использованием различных плазмообразующих сред может вызывать устойчивую модификацию их электронных свойств. Модификация поверхностей проявляется прежде всего в ослаблении явлений, связанных с использованием эффектов поля, люминесценции, фото- и поверхностной проводимости, в изменении работы выхода и др. [3]. Однако, с другой стороны, это может позволить в определенной степени активно формировать электронные свойства поверхности обрабатываемых полупроводниковых кристаллов и придавать им необходимые функциональные свойства.

Цель настоящей работы - исследовать возможность снижения рабочих напряжений полевых источников электронов, изготовленных на основе поверхностно наноструктурированных кристаллов кремния различных типов электропроводности.

Структурирование поверхностей осуществлялось в одном технологическом цикле путем осаждения островковых углеродных масковых покрытий в микроволновой плазме паров этанола на кристаллы кремния различных типов проводимости с удельным сопротивлением 0.01-0.02 $\Omega \cdot \mathrm{cm}$ после удаления естественного оксидного покрытия в низкоэнергетической плазме хладона-14 по методике, изложенной в [4]. Наноморфология поверхностей изучалась с помощью сканирующего атомно-силового микроскопа P4-SPM-MDT. В качестве зонда использовались стандартные кремниевые кантилеверы CSG10 пирамидальной формы с радиусом закругления $10 \mathrm{~nm}$ и жесткостью $0.1 \mathrm{~N} / \mathrm{m}$.

Исследования автоэмиссионных свойств кремниевых пластин осуществлялись в условиях высокого вакуума $\left(10^{-5} \mathrm{~Pa}\right)$ на диодной структуре, способной изменять расстояние между электродами с точностью до $1 \mu \mathrm{m}$.

На рисунке приведены зависимости высот выступов и напряженностей электрического поля полевой эмиссии электронов при плотности автоэмиссионного тока $50 \mu \mathrm{A} / \mathrm{cm}^{2}$ от длительности высокоанизотропного травления пластин кремния различных типов проводимости (зна-

Письма в ЖТФ, 2018, том 44, вып. 13 

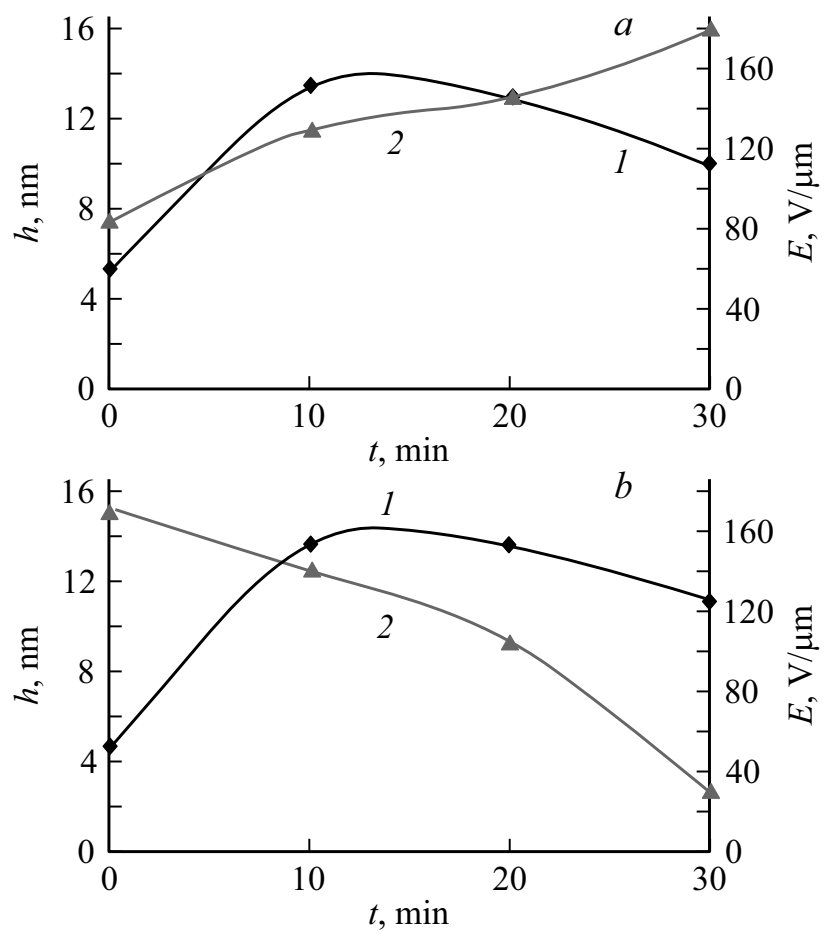

Зависимости высот выступов (1) и напряженностей электрического поля полевой эмиссии электронов при плотности автоэмиссионного тока $50 \mu \mathrm{A} / \mathrm{cm}^{2}$ (2) от длительности высокоанизотропного масочного травления пластин кремния $(100) n$ - $(a)$ и $p$-типа $(b)$ при получении атомно-чистых поверхностей травлением в плазме хладона-14.

чениям координат при $t=0 \mathrm{~s}$ соответствуют морфологические и автоэмиссионные характеристики кремниевых пластин до проведения высокоанизотропного масочного травления). Видно, что характер зависимостей высот выступов на структурированных поверхностях кремниевых пластин обоих типов проводимости от длительности маскового травления практически одинаков. В обоих случаях высоты выступов имеют максимумы при длительности травления около $10 \mathrm{~min}$. Высоты в максимумах составляют около $14 \mathrm{~nm}$. При дальнейшем увеличении длительности маскового травления высоты выступов медленно уменьшаются.

Письма в ЖТФ, 2018, том 44, вып. 13 
В отличие от изменений морфологических изменения автоэмиссионных характеристик полученных многоострийных катодных матриц с увеличением длительности масочного травления существенно зависят от типа электропроводности полупроводника. Для пластин кремния $n$-типа независимо от характера изменения высот выступов в интервале длительностей травления от нуля до $30 \mathrm{~min}$, наблюдается более, чем двукратное монотонное увеличение напряженностей полей автоэмиссии (см. рисунок, $a$ ). Для пластин кремния $p$-типа в этом интервале длительностей маскового травления, напротив, наблюдается практически трехкратное монотонное уменьшение напряженностей полей автоэмиссии, которое также происходит независимо от характера изменения высот выступов.

В настоящее время единственным аналитическим выражением, описывающим туннельную эмиссию электронов в сильных электрических полях, является формула Фаулера и Нордгейма, которая хорошо описывает автоэлектронную эмиссию из металлов в вакуум $[5,6]$ :

$$
J=A \frac{E_{i}^{2}}{\varphi} \exp \left(-B \varphi^{3 / 2} / E_{i}\right),
$$

где $A, B$ - некоторые коэффициенты, $\varphi$ - потенциал работы выхода электрона из материала катода, $E_{i}$ - электрическое поле на отдельном (усредненном) микровыступе. Величина $E_{i}$ связана со средней величиной напряженности внешнего электрического поля $E_{0}$ через коэффициент усиления поля $K$, который определяется морфологией поверхности:

$$
E_{i}=K E_{0} .
$$

Таким образом, окончательный вид аналитического выражения зависимости $j(E)(1)$ примет вид

$$
J=A \frac{\left(E_{0} K\right)^{2}}{\varphi} \exp \left(-B \varphi^{3 / 2} /\left(E_{0} K\right)\right) .
$$

Согласно выражению (3), изменение напряженности внешнего электрического поля $E$, при котором плотность автоэмиссионного тока остается фиксированной и составляет $50 \mu \mathrm{A} / \mathrm{cm}^{2}$, возможно только при обратно пропорциональном изменении коэффициента $K$ таким образом, чтобы произведение $K E_{0}$ оставалось постоянным. Однако из

Письма в ЖТФ, 2018, том 44, вып. 13 
зависимостей, приведенных на рисунке следует, что при длительностях травления больше $10 \mathrm{~min}$, когда высоты выступов начинают медленно уменьшаться, напряженности полей автоэмиссии или непропорционально увеличиваются, как в случае с кремнием $n$-типа, или уменьшаются (для кремния $p$-типа). Это свидетельствует о том, что полученные закономерности изменения наноморфологических и автоэмиссионных характеристик не могут быть интерпретированы в рамках представлений Фаулера и Нордгейма.

При ионно-плазменном травлении кремния в среде $\mathrm{CF}_{4}$ химически активными частицами являются ионы $\mathrm{C}^{+}, \mathrm{CF}_{n}^{+}$, где $n=1, \ldots, 4$, а также радикалы $\mathrm{CF}_{n}$ и нейтральные атомы фтора. При хемосорбции они образуют на кремнии монослойные адкомплексы $\mathrm{Si}-\mathrm{C}, \mathrm{Si}-\mathrm{F}$ и $\mathrm{Si}-\mathrm{C}-\mathrm{F}$ [7], которые после удаления естественного оксидного покрытия пассивируют атомно-чистую поверхность кремния. Благодаря более высокой по отношению к кремнию и углероду электроотрицательности атомарного фтора на поверхности кристаллов кремния при этом индуцируется отрицательный заряд. Непосредственно на границе кремния диполи $\mathrm{Si}-\mathrm{F}$ и $\mathrm{C}-\mathrm{F}$ ориентированы перпендикулярно поверхности раздела, придавая поверхности некоторый суммарный дипольный момент.

При осаждении островкового субмонослойного углеродного маскового покрытия из плазмы паров этанола благодаря низкой энергии химической связи $\mathrm{C}-\mathrm{C}(2.74 \mathrm{eV})$ наиболее вероятным является формирование цепочечных комплексов $\mathrm{Si}-\mathrm{C}-\mathrm{C}$. . С и C-C-C. . С. В процессе осаждения они „замуровывают“ оставшиеся после плазмохимического травления кремния полярные комплексы $\mathrm{Si}-\mathrm{F}$ и $\mathrm{C}-\mathrm{F}$, а также различные дефекты упаковки углеродного покрытия. С увеличением толщины слоя разориентация диполей увеличивается, а суммарный дипольный момент поверхности уменьшается [3].

В отсутствие масочного травления величина потенциального барьера при автоэмиссионных измерениях зависит от толщины слоя островковой фторуглеродной диэлектрической поверхностной фазы, в основании которой находится монослой карбида кремния. При этом автоэмиссия, так же как в случае с естественным оксидным покрытием, будет осуществляться за счет двухступенчатого туннелирования электронов из зоны проводимости кремния через карбид-кремниевый диэлектрический барьер во фторуглеродную поверхностную фазу и затем в вакуум. Кроме того, носители, инжектированные из кремниевой подложки в поверхностный слой $\mathrm{Si}-\mathrm{CF}_{m}$, взаимодействуют с

Письма в ЖТФ, 2018, том 44, вып. 13 
дефектами, расположенными в его объеме. Результатом этого является захват носителей на ловушечные центры, который за счет кулоновской блокады приводит к дополнительному увеличению напряженности поля автоэмиссии. Так как при прочих одинаковых условиях работа выхода электронов из полупроводников $n$-типа меньше, чем из полупроводников $p$-типа, напряженность поля, обеспечивающая фиксированный ток автоэмиссии, у кремниевых катодных матриц на основе кристаллов $n$-типа в отсутствие масочного травления меньше.

В процессе высокоанизотропного травления кремния через углеродсодержащую маску в среде хладона-14 за счет ограниченной селективности травления одновременно с увеличением высоты выступов происходит постепенное уменьшение толщины маски. При длительностях травления больше 10 min высоты выступов постепенно уменьшаются за счет ускоренного травления заостренных вершин (кривые 1 на рисунке). Уменьшение толщин масковых покрытий приводит к увеличению отрицательного суммарного дипольного момента поверхности вершин выступов, вызванного хемосорбцией на кремнии атомов фтора. Для перемещения электрона через дипольный слой необходимо совершить дополнительную работу. Уменьшение высот выступов, которое вместе с уменьшением коэффициентов усиления поля $K$ сопровождается увеличением дипольного момента поверхности, приводит для пластин кремния $n$-типа к росту работы выхода и напряженностей полей автоэмиссии (кривая 2 на рисунке, $a$ ). Качественно это соответствует выражению (3). Однако для кремния $p$-типа этого не наблюдается (кривая 2 на рисунке, $b$ ). Причиной этого является следующее.

Наличие на поверхности кристаллов кремния полярных комплексов $\mathrm{Si}-\mathrm{F}$ и $\mathrm{C}-\mathrm{F}$ с электроотрицательными атомами фтора приводит к обеднению основными носителями приповерхностной области у кристаллов кремния $n$-типа и обогащению основными носителями у кристаллов кремния $p$-типа. В соответствии с этим глубина проникновения электрического поля диполя в приповерхностную область полупроводников, оцениваемая по дебаевской длине экранирования, для кристаллов кремния $n$-типа увеличивается (что вносит вклад в увеличение рабочих напряжений), а для кристаллов $p$-типа, напротив, уменьшается. Благодаря этому величина туннельного барьера при автоэмиссионных измерениях для кремния р-типа становится существенно меньше. С увеличением длительности масочного травления за счет уменьшения толщины углеродсодержащей маски и увеличения

Письма в ЖТФ, 2018, том 44, вып. 13 
суммарного дипольного момента поверхностей величина туннельного барьера для кристаллов кремния $p$-типа продолжает уменьшаться, а для донорного полупроводника увеличиваться. Это выражается в соответствующих уменьшениях напряженностей внешних полей автоэмиссии для кристаллов кремния $p$-типа и их увеличении для кристаллов $n$-типа.

Исследование выполнено за счет гранта Российского научного фонда (проект № 16-19-10033).

\section{Список литературы}

[1] Marcus R.B., Ravi T.S., Gmitter T., Chin K., Liu D., Orvis W.J., Ciarlo D.R., Hunt C.E., Trujillo J. // Appl. Phys. Lett. 1990. V. 56. № 3. P. 236-238.

[2] Яфаров Р.К. // ФТП. 2014. Т. 48. В. 4. С. 529-534.

[3] Оура К., Лифбии, В.Г., Саранин А.А., Зотов А.В., Катаяма М. Введение в физику поверхности. М.: Наука, 2006. 490 с.

[4] ЯФаров Р.К., Шаныгин В.Я. // ФТП. 2017. Т. 51. В. 4. С. 558-562.

[5] Fowler R.H., Nordheim L.W. // Proc. Roy. Soc. Lond. A. 1928. V. 119. N 781. P. 173-181.

[6] Усанов Д.А., Яфаров Р.К. Методы получения и исследования самоорганизующихся наноструктур на основе кремния и углерода. Саратов: Саратов. гос. ун-т, 2011. $126 \mathrm{c}$.

[7] Яфаров Р.К. Физика СВЧ вакуумно-плазменных нанотехнологий. М.: Физматлит, 2009. $216 \mathrm{c}$. 